American Journal of Pharmaceutical Education 2019; 83 (5) Article 6745.

\title{
RESEARCH
}

\section{Promoting Patient Care Through Communication Training in a Pre- clerkship Pharmacy Education Course in Japan}

\author{
Denise A. Epp, PhD, MSEd, ${ }^{\mathrm{a}, \mathrm{b}}$ Toshio Kubota, $\mathrm{PhD},{ }^{\mathrm{c}}$ Motofumi Yoshida, MD, PhD, ${ }^{\mathrm{d}}$ \\ Junji Kishimoto, $\mathrm{PhD},{ }^{\mathrm{e}}$ Daisuke Kobayashi, $\mathrm{PhD},{ }^{\mathrm{b}}$ Takao Shimazoe, $\mathrm{PhD}^{\mathrm{b}}$ \\ ${ }^{a}$ Center for Advancing Pharmaceutical Education, Daiichi University of Pharmacy, Fukuoka, Japan \\ ${ }^{\mathrm{b}}$ Graduate School of Pharmaceutical Sciences, Kyushu University, Fukuoka, Japan \\ ${ }^{\mathrm{c}}$ Center of Pharmaceutical Care for Community Health, Daiichi University of Pharmacy, Fukuoka, Japan \\ ${ }^{\mathrm{d}}$ Faculty of Medicine, International University for Health and Welfare, Narita, Japan \\ ${ }^{\mathrm{e}}$ Faculty of Medical Sciences, Kyushu University, Fukuoka, Japan \\ Submitted August 23, 2017; accepted January 29, 2018; published June 2019.
}

Objective. The purpose of this study was to teach communication skills for patient care to preclerkship students and observe changes in student perspectives towards communication from pre- to post-training.

Methods. Two cohorts of fourth-year pharmacy students completed an eight-week pre-clerkship training course designed to improve their communication skills. The course involved class discussions and in-class research of medications, practicing communication skills, learning to give science-based responses, and developing an awareness of patient education for lifestyle, self-medication, quality of life, and medication adherence. A comparison of students' pre- and post-training responses to a questionnaire were used to assess changes in students' ability and confidence in communicating with patients. An exploratory factor analysis was used to analyze and compare the data results.

Results. Students' mean post-training scores for perceived ability to make small talk and confidence to communicate with patients increased compared to pre-training scores. Based on the results of the exploratory factor analysis, the greatest increase in students' scores was in the area of patient education skills.

Conclusion. The pre-clerkship communication training improved student understanding of the pharmacy communication skills needed to conduct effective patient education and pharmacist-patient interaction beyond dispensing, affirming the theory that specialized communication training before students' begin a clerkship may be essential.

Keywords: communication training, patient care, patient education, Japanese pharmacy education

\section{INTRODUCTION}

Around the world, changes to pharmacy education programs have reflected changes occurring in pharmacy practice, and have led to a greater focus on patient care, self-medication, evidence-based health outcomes, and support for health care cost reductions. Guidelines for clinical practice are published by professional pharmacist associations and often adopted by pharmacy schools. Some examples of these documents are the Blueprint for Pharmacy (Canada), Standards of Practice for Clinical Pharmacists (US), the Annual Report of the Japan Pharmaceutical Association (JPA), Good Pharmacy Practice (International

Corresponding Author: Denise A. Epp, 22-1 Tamagawa, Minami-ku, Fukuoka, Japan 815-8511. Tel: +81-92-541-0161 (ext. 370). E-mail: depp@daiichi-cps.ac.jp
Pharmaceutical Federation (FIP) and World Health Organization (WHO)), and more recently, the Pharmacy as a Gateway to Care (FIP). ${ }^{1-5}$ These guidelines emerged from various pharmacy initiatives conducted to produce pharmacists capable of taking responsibility for patient health, playing distinct roles in the medical community, and taking some of the patient-care burden away from physicians. The 2016 Japanese Annual Health, Labor, and Welfare Report stated that there were approximately 311,000 physicians and 288,000 pharmacists working in Japan, and 57,800 pharmacies nationwide. ${ }^{6}$ The process of separating the role of prescribing from that of dispensing has been an ongoing challenge in Japan. In recent years, the expansion of the pharmacists' role has become a priority in the movement toward separating these two responsibilities, but progress takes time. 


\section{American Journal of Pharmaceutical Education 2019; 83 (5) Article 6745.}

Recently, the Japanese Ministry of Health, Labor, and Welfare (MHLW) has encouraged pharmacists to be more involved in patient care and to participate actively on medical teams. ${ }^{7}$ For example, in 2014, the MHLW gave pharmacists permission to do "point of care" testing in pharmacies. ${ }^{8}$ In 2015 , pharmacists received elective training in how to conduct home visits with patients, which was the government response to the aging population and its increasing burden on the health care system. ${ }^{8}$ In 2016, the Japanese government launched an initiative called "family pharmacy," where pharmacists become a family pharmacist working with the same patients through all their pharmaceutical needs. ${ }^{3}$ As part of the program, pharmacists conduct dispensing procedures and drug reviews for prescribed medications, counseling, and patient education to promote selfmedication and reduce overall health costs. ${ }^{7}$ These communication-based initiatives have also been included in the Japanese reimbursement scheme, with higher fees being paid for services rendred beyond duispensing.

With these changes in mind, the expanded role of the pharmacist must be considered carefully in the development of pharmacy education programs. Although progress tends to be slow in Japan, the new health initiatives have instigated a movement toward pharmacists providing clinical patient care, and this care is dependent upon communication. The pharmacy and hospital clerkships in the fifth year of study are often the pharmacy students' first exposure to having conversations with patients as a health professional, which illustrates the pressing need for more opportunities to practice effective communication with patients, other professionals, and the community in general during pre-clerkship courses. Communication-specific training should include skill practice and the application of attained knowledge to realistic situations involving patients. ${ }^{9,10}$ The challenge for pharmacy education programs is to train students to attain higher-level communication skills as well as dispensing competencies.

Despite recent initiatives introduced by the government, colleges and schools have been hesitant to change their already full curriculums from science-based dispensing to training programs which include clinical patient care. This is in part due to a rigorous licensing examination that graduates must be prepared to pass. Unclear guidelines and overly general standards of the 2013 Model Core Curriculum for Pharmacy Education in Japan left schools wondering how to educate students in communication and patient education as it relates to clinical practice while maintaining a competitive edge in national test scores and rankings. ${ }^{11}$ The 2015 Clinical Pharmacy Guidelines released by the Japanese Ministry of Education, Science, and Technology (MEXT) states the word "communication" in association with the role of pharmacists on the hospital wards, but the wording becomes "advise" to describe the role of community pharmacists. ${ }^{12}$ At the same time, the MHLW released policies recently that set expectations for pharmacists to communicate with patients in the community pharmacies. ${ }^{7}$ These initiatives have led to a discrepancy between the instruction provided in university pharmacy programs and governmental expectations pharmacy practice.

The clinical pre-clerkship program was started in 2006 at the same time Japan shifted from a four-year research focused program to a six-year clinical pharmacy program. The pre-clerkship focuses mainly on the core competencies necessary for performance on an objective structured clinical examination (OSCE), administered in the fourth year of study, and for the community and hospital clerkships that follow in the fifth year. The guidelines produced by MEXT outline the necessary skills students need for their clerkship experiences. ${ }^{7,12}$ The new government policies, required that students receive specialized training in communication skills that focuses on patient education and how to initiate discussions with patients about lifestyle, clinical outcomes, and effective treatment of diseases.

Many pharmacies in Japan are located in close proximity to a clinic or hospital and provide service to patients who receive prescriptions from those institutions. This system means that patients often go to different pharmacies for different prescriptions. As the health care system in Japan moves to a more economically competitive health care paradigm where patients see a "family pharmacist" for all their needs, pharmacists will be required to communicate effectively to build rapport and attract patients to their pharmacy. This change will require pharmacists to adopt a more patient-centered approach. ${ }^{13}$ The instructions and directions the pharmacist provides to patients regarding their medications should be clear and straightforward and include a discussion of adherence, possible side effects, precautions, and warnings. ${ }^{14}$ Verbal communication provides positive reinforcement and encouragement for the patient on a psychological level and improves their attitude towards and behavior regarding selfmanagement and adherence. ${ }^{15}$ Therefore, pre-clerkship students need to learn how to exchange all this information with the patient during a brief encounter in the pharmacy.

While mastery of communication is not the goal for students in the pre-clerkship course, gaining an awareness of the influence of a patient's emotional state on their health behaviors, together with an understanding of common diseases and medical conditions, will help students in future situations where they need to communicate and 


\section{American Journal of Pharmaceutical Education 2019; 83 (5) Article 6745.}

build professional relationships. This period of training provides students with the basic skills that can be expanded on and improved during the clerkship. ${ }^{16}$ Identifying such behaviors through observation during their clerkships will underscore what students learn in the pre-clerkship. The students will understand that patient outcomes are influenced by communication with pharmacists. The clear understanding of the purpose of communication is essential to the deliberate practice of interacting with others and thinking beyond scripted dialogue when talking to patients. Gaining a clear understanding of the expectations of their role in the pharmacy and their part in the medical team leads pharmacy students to develop the effective communication skills needed to solve a problem or provide the patient with the information necessary to resolve the problem. These are concepts reinforced through the discussions and group work completed in the pre-clerkship communication training class. This education and training are reinforced with practice, but the experience of the clerkship loses its purpose if students cannot make the connection between the learned theory and the practical use of the communication skills. ${ }^{17}$

A study by Hagemeier and colleagues involving interprofessional and interpersonal communication for health professions students created a communication course with the understanding that the motivation to communicate comes from one's self-beliefs (self-efficacy) and having knowledge and skill in communication. ${ }^{9}$ The study found that pharmacy students had lower selfefficacy beliefs compared to nursing and medical students and maintained this lower self-efficacy into practice, particularly in their ability to communicate with the health care team, in reaching common ground with patients, involving patients in health care plans, and contributing to the health care team. The conclusion was that skills training had a positive impact on the students, and they were more motivated to use those skills and knowledge to communicate with patients and other health care professionals in the future. ${ }^{9}$

Our research question asked how special communication training in pre-clerkship studies influences student perspective and confidence in communication and patient education. The primary objective was to improve students' clerkship experiences and ultimately pharmacy practice with communication skills training during the pre-clerkship. This study was conducted through a specially created eight-week communication skills course to challenge the students to gain greater awareness and understanding of how to talk to patients and to provide them with opportunities to practice communicating for improved patient care. The training focused on developing communication skills for patient care and education and building the students' confidence in using those skills before starting their clerkships. This qualitative educational training combined with quantitative research methods sought to understand how communication training changed students' perspectives regarding their communication skills.

\section{METHODS}

The study began in 2014 with the creation and testing of a communication questionnaire that was translated from English and conducted in Japanese with 75 fifthyear post-clerkship students. The questionnaire was modified in 2015 to fit the fourth-year pre-clerkship pharmacy students, and was administered to all 106 fourth-year students at the beginning and end of the communicationtraining course.

The pre-clerkship communication training course introduced students to a "research and discussion" style of active learning that required an understanding of patient needs and lifestyle as the students had to develop verbal answers to possible patient questions. The eight 90-minute communication classes at the beginning of the preclerkship training were conducted in English in collaboration with a pharmacist during the compulsory Clinical Pharmacy English class. The patient education topics covered instructions regarding missed doses, interpreting over-the-counter (OTC) medicine labels, and understanding how to discuss the indications and side effects of hypertension, dyslipidemia, Type 2 diabetes mellitus, anaphylaxis, and influenza antiviral medications. The collaborating pharmacist provided a list of common medications used, and these were included in the research component of the communication class.

The students were asked to research one or two related medications on the Internet as a pre-study assignment and then provided with corresponding English texts and questions to be discussed that focused on how a pharmacist should respond to a patient. The readings and small group discussions of six to eight students provided the knowledge and ideas to professionally answer each question. These questions were designed to encourage students to consider the lifestyle and needs of the patients through empathy, as well as how to promote patient adherence and self-management. They were encouraged to share scientific-based information with patients, as well as to give them encouragement and advice. Role-play activities with dialogues between a pharmacist and a patient provided examples of how to converse with a patient. An assignment requiring the students to create a pamphlet to serve as a visual tool to be used for patient education and meeting individual patient needs concluded the course content. Through this research, discussion, and 


\section{American Journal of Pharmaceutical Education 2019; 83 (5) Article 6745.}

practice, the students were introduced to what communication can and should be in the pharmacy.

The four-part questionnaire with a five-point Likert scale was adapted from basic clinical practice in Japan and communication assessment tools, such as the CalgaryCambridge medical interview, the SEGUE Framework, and the Teramachi Communication Scale (Japanese) (Appendix 1). ${ }^{7,12,18-21}$ Each section was divided into questions that supported communication concepts including small talk, communication with patients, method of communication, and pharmacist behavior and attitude toward communication. The questionnaire was given to the fourth-year pre-clerkship students in pre- and posttraining for two consecutive years and asked the students about their ability to communicate, their confidence in communicating with patients, and their opinion about how pharmacists should communicate with patients. The ranked, five-point Likert scale responses were $1=$ never can do, $2=$ cannot do, $3=$ cannot say either way, $4=$ can do, and $5=$ always can do. The questionnaire was translated into Japanese so that the wording corresponded to the meaning of the original English version. The reliability of the translation was confirmed by a bilingual student and considered sufficient. All students who participated in the study provided signed consent and were given a reference number to hide their identities from the investigators. If a questionnaire included incomplete responses or the corresponding consent form was missing, the questionnaire data were rejected. Cronbach alpha was applied to confirm the reliability of the data. ${ }^{22}$

Questionnaire data were collected over two consecutive years and analyzed using JMP Pro 12 software (SAS Institute Inc., Cary, NC). ${ }^{23}$ An exploratory factor analysis was performed first with the 2016 data group, and then the factors were applied to the 2015 data to confirm reliability and reproducibility of the analysis. Paired $t$ tests and Wilcoxon signed-rank tests were performed using JMP Pro 12 to determine the significance $(p \leq .05)$ of students' pre- and post-training responses for the communicationspecific skills in part two of the questionnaire. ${ }^{24} \mathrm{~A}$ confirmatory factor analysis using a path diagram on AMOS 24 software (IBM SPSS, Chicago) determined dependability and goodness of fit. ${ }^{25-27}$ Differences in sample size between the groups were verified using effect size Cohen's d to confirm the strength of the relationship between the study groups. ${ }^{28}$ Finally, the changes in scores pre- and post-training were evaluated using the $\mathrm{McNemar}$ test on JMP Pro $12 .{ }^{29}$

\section{RESULTS}

A total of 208 fourth-year students voluntarily participated in the study over two years. In the first year
(2015), $65 \%$ of the students were female and $35 \%$ were male, and in the second year (2016), 58\% were female and $42 \%$ were male. The age of the students ranged from early 20 s to late 40 s, with the average age of students in 2015 being 24 years old and 25 years old in 2016 .

The final grades for the class were calculated based on observed participation in the discussions and role-play activities, cooperation with partners in group activities, and ability to formulate clear, simple answers to patient questions and provide knowledge-based responses for adherence and health outcomes on the weekly mini-tests. The answers developed during class were evaluated based on content rather than English ability, but the final examination included a content and language component. The final project, to make a pamphlet for visual support for patient education, had the same weight as the final examination and was assessed with a rubric. The final average course grades for the 2015 and 2016 cohorts were almost the same at $77 \%$ and $79 \%$, respectively.

Factor analysis with oblique rotation was applied to part 2 of the questionnaire, which contained four communication-specific questions about initiating communication (question 4), using verbal and nonverbal skills (question 5), getting information from the patient (question 6), and providing patient education (question 7). This factor analysis loaded to three factors, and they were named: explaining and advising for dispensing (factor one), responding to the patient (factor two), and initiating communication with patients (factor three) (Table 1). Closer inspection of these factors and the $p$ values from pre- and post-training enabled a comparison of student responses between the two years in which data were collected (Table 2). A Cronbach alpha coefficient of 0.82 supported the reliability of the collected data. ${ }^{22}$ The Cohen's d effect size also showed small variance between the two group responses with a d value of 0.1 .

The mean scores increased from pre- to post-training for all factors in both groups, with significance observed for the three factors in 2016, but only for factor one in 2015 ( $p=.04$ ) (Table 2). The questions of factor one were mainly patient education concepts and were covered specifically in the training class. With the 2016 group, seven out of the eight questions from factor one showed strong significance in the increased scores $(p \leq .001$ to $p=.03$; data not shown). There was less significance seen between the pre- and post-training mean scores in factor two and factor three, but within these factors, using questions appropriately $(p \leq .002)$, praising patients for progress $(p=.01)$, and describing the purpose for talking to the patient $(p \leq .01)$ had significant increases. Based on the evidence of the McNemar test, the changes in the pre- to post-training response scores reflected an improvement 


\section{American Journal of Pharmaceutical Education 2019; 83 (5) Article 6745.}

Table 1. Factor Loading to Three and Naming Factors for Exploratory Factor Analysis of Fourth-year Pre-Clerkship Pharmacy Students’ Responses to a Pharmacy Communication Questionnaire

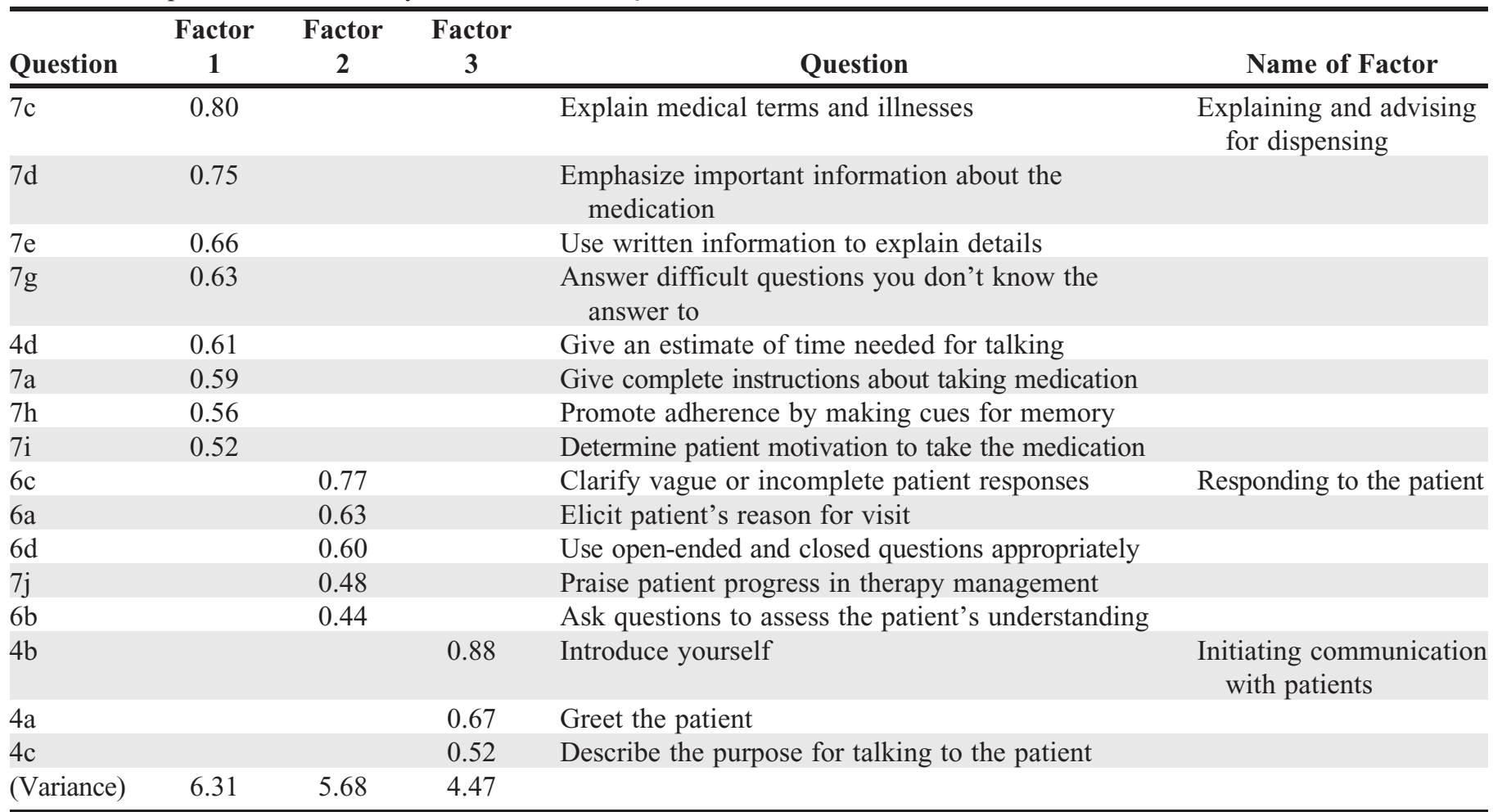

Promax rotation after PCA

with all but four of the question 7 patient education questions $(7 \mathrm{~d}, 7 \mathrm{f}, 7 \mathrm{j}$, and $7 \mathrm{k}$; Table 3 ).

In addition, a confirmatory factor analysis using a path diagram for the three factors and 16 indicators supported the findings of the exploratory factor analysis (Figure 1). The path coefficients showed medium to large strength. ${ }^{25}$ The root mean square error of approximation (RMSEA) was 0.09 , which is considered a reasonable fit. The adjusted goodness of fit (AGFI) was 0.80, and less than 0.95 is a good fit. ${ }^{26}$ The reliability of the path diagram supported the strength of student responses regarding communication in patient education.

Table 2. The Increase in the Three-Factor Scores of Fourthyear Pre-Clerkship Pharmacy Students from Pre- to PostTraining for Pharmacy Communication

\begin{tabular}{lcclll}
\hline & \multicolumn{2}{c}{ Y4 2015 } & & \multicolumn{2}{c}{ Y4 2016 } \\
\cline { 2 - 3 } \cline { 6 - 7 } Factors & M (SD) & $\boldsymbol{p}$ Value & & M (SD) & $\boldsymbol{p ~ V a l u e ~}$ \\
\hline Factor 1 pre & $25.4(4.41)$ & .04 & & $26.3(4.47)$ & $<.001$ \\
Factor 1 post & $26.4(4.12)$ & & & $28.3(4.26)$ & \\
Factor 2 pre & $17.1(2.90)$ & .08 & & $17.4(2.66)$ & $<.001$ \\
Factor 2 post & $17.8(2.33)$ & & & $18.4(2.75)$ & \\
Factor 3 pre & $12.2(1.66)$ & .67 & & $11.9(1.69)$ & $<.002$ \\
Factor 3 post & $12.3(1.44)$ & & $12.2(1.83)$ & \\
\hline
\end{tabular}

$p \leq .05$ paired $t$-test
The questionnaire also inquired about the students' ability to make small talk with patients. The students identified the topics they felt they could use to initiate small talk about, ranging from the weather and the news to personal information, or why they did not believe they would be able to communicate with patients, if that was the case. This question led to a comparison made between the number of students with the perceived ability to make small talk (Question 1) and the number with confidence in being able to communicate with patients in their clerkships (Question 11) for both years (data not shown). Out of the 136 pre-training student responses, $61 \%$ believed they could make small talk with patients on a variety of topics, but their confidence responses were only $22 \%$. The post-training responses showed an increase to $78 \%$ of the students with small talk ability and more confidence responses than pre-training at $32 \%$. There was a marked increase in positive responses observed between the pre- and post-training responses for small talk, but not as much in their confidence. Although their "yes" responses increased $17 \%$ from pre- to post-training in the area of ability to have small talk with patients, and $10 \%$ in their self-perceived confidence to communicate in their clerkships, the number of "no" responses for confidence remained significantly higher from pre- to post-training. 


\section{American Journal of Pharmaceutical Education 2019; 83 (5) Article 6745.}

Table 3. Contingency Analysis of the Changes in Q7 Patient Education Responses of Fourth-year Pre-Clerkship Pharmacy Students from Pre- to Post-Training in Pharmacy Communication

\begin{tabular}{lcccccc}
\hline Question from Communication Questionnaire & P - P & P - N & N - P & N - N & Chi-square & $p$ Value \\
\hline 7a. Give complete instructions about taking medication & 55 & 17 & 33 & 31 & 5.12 & .02 \\
7b. Use easy to understand language (no medical jargon) & 77 & 6 & 29 & 24 & 15.11 & $<.001$ \\
7c. Explain medical terms and illnesses & 33 & 16 & 31 & 56 & 4.79 & .03 \\
7d. Emphasize important information about the medication & 54 & 20 & 26 & 36 & 0.78 & .38 \\
7e. Use written information to explain details & 26 & 12 & 30 & 68 & 7.71 & .01 \\
7f. Make posters and pamphlets & 61 & 27 & 20 & 28 & 1.04 & .31 \\
7g. Answer difficult questions you don't know the answer to & 29 & 17 & 35 & 55 & 6.23 & .01 \\
7h. Promote adherence by making cues for memory & 38 & 14 & 42 & 42 & 14.00 & $<.002$ \\
7i. Determine patient motivation to take the medication & 28 & 17 & 43 & 48 & 11.27 & $<.008$ \\
7j. Praise patient progress in therapy management & 71 & 16 & 25 & 24 & 1.98 & .16 \\
7k. Collaborate with the patient to solve problems & 67 & 19 & 29 & 21 & 2.08 & .15 \\
\hline
\end{tabular}

$\mathrm{n}=136 ; \mathrm{P}=$ positive responses, ie, a 4 or $5 ; \mathrm{N}=$ non-positive responses, ie, score of 1,2 or 3 ; McNemar test Chi-square $p \leq .05$

${ }^{*}$ Pre-training to post training, positive response to positive response

In comparing the Hagemeier and colleague's questionnaire from 2014 with the questionnaire used in this study, we identified five questions on interpersonal communication on both survey instruments that were comparable. ${ }^{9}$ These questions included asking if the students were confident in their ability to listen (6b), communicate information (7d), address patient feelings (4d), involve patients in health care plans $(7 \mathrm{k})$, and convey knowledge (7c). The Japanese student responses showed greatest improvement in the question addressing patient feelings, with an increase of $23 \%$ pre- to post-training, while the other four questions had increases of $5 \%$ to $9 \%$ (data not shown). In contrast, the greatest improvement pre- to post-training for the American students centered on involving patients in health care plans (a 49\% increase) and conveying knowledge to patients $(44 \%){ }^{9}$

\section{DISCUSSION}

The pre-clerkship education provided the students with a risk-free opportunity to practice dispensing skills and gain a critical awareness of their communication skills before entering clerkships. For many students, it was their first experience with passing on a particular message to the patients that would potentially result in a positive patient response, eg, lifestyle change, drug adherence, or improved quality of life. The skills assessed in this short-term course were the ability to formulate a sound answer in simple language to the provided patient questions and responses and to work effectively with a partner or team in their small group discussions during class. Improvement was observed in the quality of the mini-test responses to the proposed patient questions, and many students were able to raise their grades on these tests throughout the course. The case studies presented in class were used to help students think critically about various human and uncontrolled factors involved in any situation, such as the lifestyle and personality of the patient, instead of just memorizing answers to predetermined questions. This exposure to the reality of communicating with patients provided insight into being prepared to interact with patients and to perform their professional responsibilities within the team. ${ }^{30}$ Many students noted afterwards that they struggled to express themselves in the discussions and felt pressured to produce answers within the specified time limit.

The exploratory factor analysis of the communication skills section of the questionnaire produced three factors categorized based on pharmacists' overall communicative function in the pharmacy with explaining and advising, responding to patients, and initiating communication. The confirmatory analysis supported this pattern with strong correlations and higher scores in the path diagram. In particular, it showed strength between factor one, "explaining and advising for dispensing" and factor two, "responding to the patient." These two factors mimicked the necessary communication skills for patient education and counseling in the pharmacy. Factor three "initiating communication with patients" was a topic widely covered in the pre-clerkship studies with role-play practice and simulated patients.

In this study, the three factors were compared preand post-training to evaluate the effect of the eight-week communication skills training program on student responses in both the 2015 and 2016 groups. The total mean scores for all three factors significantly increased from pre- to post-training in the 2016 group. We concluded that the increase in student response scores was the result of increased knowledge and awareness of effective communication with patients. In the 2015 group, the increase in scores was significant only for factor one. The difference 


\section{American Journal of Pharmaceutical Education 2019; 83 (5) Article 6745.}

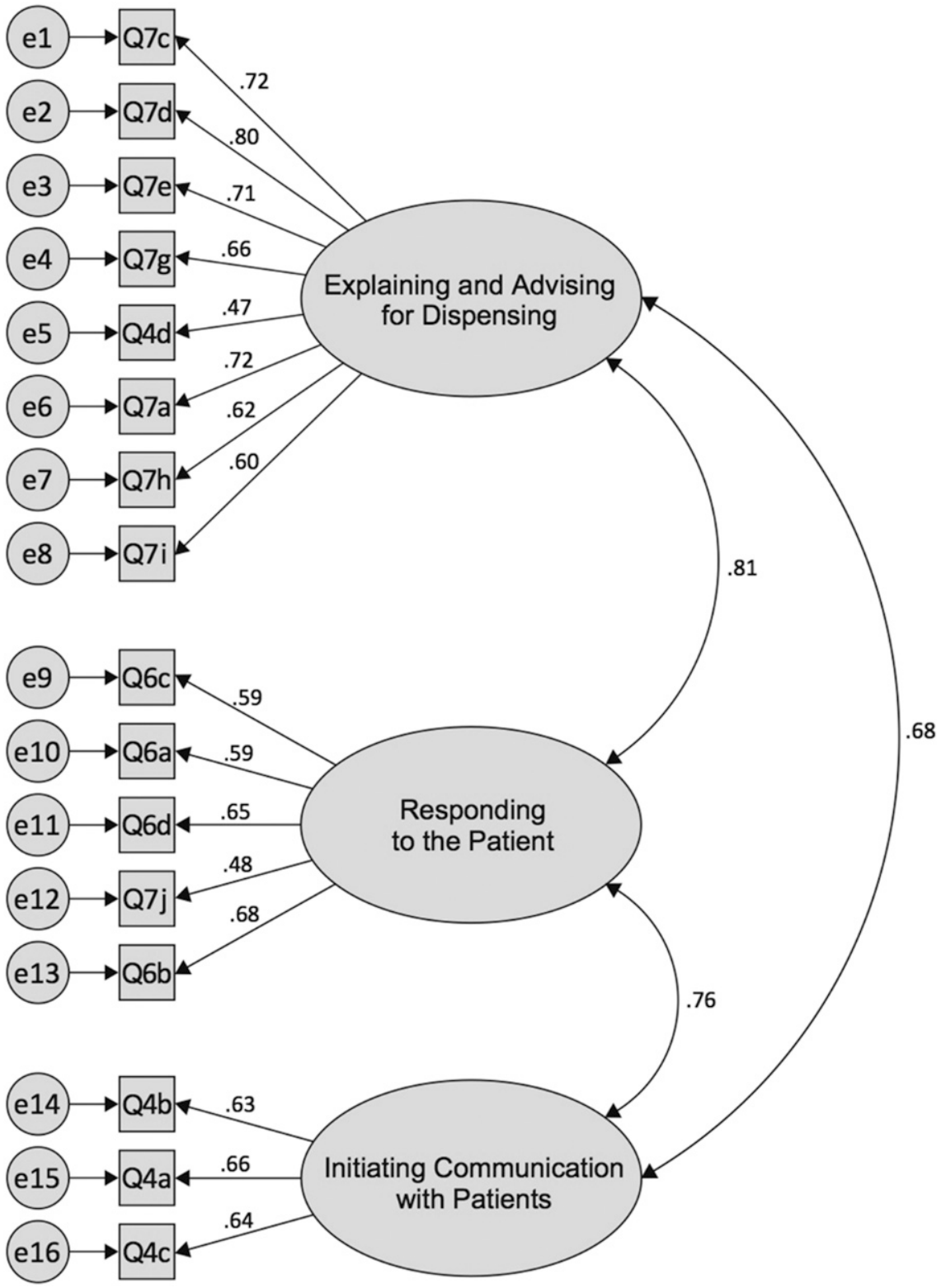

Figure 1. Structured Equation Modeling of Communication Skill Questions for Y4 2016

Fit summary: RMSEA .09, AGFI $.80, p \leq .01$, Chi-square 199.81, DF 1.98

between the 2015 and 2016 scores could have been the result of the professors' improved teaching skills or the academic strength and motivation of the students that year.

In factor one, the majority of the correlation came from question 7 of the questionnaire, which focused on patient education when dispensing medication. For example, the importance of using simple, clear language was a point discussed in detail during class and reinforced through practice because, up to that point, the students had learned only medical terms (medical jargon) that a typical English-speaking patient would not understand. In Japanese, the characters used for medical terms hold meaning that any Japanese person could understand, but in English there are major differences between the medical terms pharmacists use when speaking with a colleague and the lay terms they would use when speaking with a patient. Other concepts that were enforced in the course included encouraging adherence by creating memory cues with the patient, determining the motivation of the patient to follow the pharmacist's advice, explaining the necessity of not missing a dose of medication, and praising patient progress in therapy management. In-class readings and discussions brought these topics to the students' attention, and then the topics became the focus of test questions. The reinforcement of these patient 


\section{American Journal of Pharmaceutical Education 2019; 83 (5) Article 6745.}

education points in class probably made the strongest impression on the students and led to a larger increase in mean scores.

The contingency analysis on question 1 of the questionnaire showed that the majority of students believed they could make small talk with patients on a variety of subjects. This self-awareness came from understanding the necessity of small talk to develop a professional relationship with patients. A pharmacist-patient relationship of mutual trust and understanding is established through dialogue. ${ }^{13,31}$ Students' lack of experience in the pharmacy at this point in their training may have contributed to their lack of confidence in communicating with patients, as indicated later by the slight increase in scores from pre- to post-training on question 11. A comparison of the changes in student self-efficacy belief responses from the Hagemeier and colleague's study and the Japanese student responses in this study reflected similar progress in developing more effective interpersonal communication skills from pre- to post-training. ${ }^{9}$

The limitations of this study were reflected in the accuracy of the student responses, which were reliant on the timing of the questionnaire and the motivation of the students to answer. The more time passed after the clerkship for the students to complete the questionnaire, the less motivated they were to respond accurately. The number of repeater students, who had to repeat the year of studies due to personal or academic reasons, influenced the final grades, as well as the attitude and learning in some of the classes. These students continue to perform at a lower academic level after becoming a repeater. Both cohorts received their training at the beginning of the fourth-year pre-clerkship studies, after completing the same curricular program taught by the same professor. The university curriculum department explained that the difference in responses of the two groups could have been an extension of stricter admission guidelines in the second year and the division of those classes by academic level throughout the pre-clerkship studies. These changes may have influenced students' responses on the questionnaire and their motivation to participate in a research and discussion style of learning in class.

Concerns regarding the translation reliability led to updated versions of the questionnaire in which some wording was fixed to make it easier for the students to understand. For example, the word for "empathy" in Japanese is complicated, so on the questionnaire, we used the expression "understanding the patient," the meaning of which is slightly different between the two languages. It would be of value to compare the questionnaire responses pre- and post-training with the course, which was taught fully in Japanese, although it presently allows the students to use English as a tool to further their communication skills.

Future studies will consider how students' communication training during pre-clerkship studies affects the clerkship experience in terms of patient care and patient education and the confidence level of the students in their ability to communicate in the pharmacy. The results of a post-clerkship questionnaire could provide evidence regarding the influence the communication training class had on the students by comparing responses of students who received the additional communication training and those who did not.

\section{CONCLUSION}

This communication-training program for preclerkship pharmacy students in Japan was implemented with the developing role of patient care in pharmacy practice specifically in mind. Throughout the training course, communication skills were introduced and practiced through research, discussion, role-play, and visual materials like pamphlets, which created a skill base that students could apply in future clerkships. The questionnaire inquired about student perspectives on communication with patients in the pharmacy, and the data from the two fourth-year groups were analyzed for changes in perspective and understanding from pre- to post-training. There was an increase in the mean response scores for both preclerkship groups. The results indicated that the training course increased student understanding, particularly in patient education skills and in communicating with patients beyond giving basic dispensing explanations, promoting greater awareness about pharmacist-patient interaction in the pharmacy. A communication skills training course in pre-clerkship studies ensures that the pharmacy students will develop core competencies in communicating with patients. It also provides opportunities to practice the skills, so the students develop confidence in their patient education skills, which they will use in their future clerkships.

\section{ACKNOWLEDGMENTS}

We would like to thank Dr. Makoto Kikukawa of Kyushu University, Department of Medical Education, for his continuous support of this educational project and for assisting us by providing the path diagram using the Amos 24 Software.

\section{REFERENCES}

1. Task Force on a Blueprint for Pharmacy. Blueprint for pharmacy: the vision for pharmacy. Ottawa (ON): Canadian Pharmacists Association; 2008.

2. American College of Clinical Pharmacy. Standards of practice for clinical pharmacists. Pharmacotherapy 2014;34(8):794-797. https:// 


\section{American Journal of Pharmaceutical Education 2019; 83 (5) Article 6745.}

www.accp.com/docs/positions/guidelines/standardsofpractice.pdf. Accessed June 20, 2017.

3. Annual report of JPA: 2016-2017. Japan Pharmaceutical Association. www.nichiyaku.or.jp. Accessed June 20, 2017. 4. International Pharmaceutical Federation (FIP). Joint FIP/WHO guidelines on GPP: Standards for quality of pharmacy services. The Hague: International Pharmaceutical Federation; 2011. www.fip.org/ www/uploads/database_file.php?id=331\&table_id=. Accessed June 22, 2017.

5. International Pharmaceutical Federation (FIP). Pharmacy as a gateway to care: Helping people towards better health. The Hague: International Pharmaceutical Federation; 2017. fip.org/files/fip/ publications/2017-04-Pharmacy-Gateway-Care.pdf. Accessed June 22, 2017.

6. Annual health, labor, and welfare report 2016: Overview of health and medical services. Ministry of Health, Labor, and Welfare (MHLW). http://www.mhlw.go.jp/english/wp/wp-hw10/d1/02e.pdf. Accessed on June 22, 2017.

7. The Vision for Patient-Centered Pharmacy 2015. (Translated from Kanjano yakkyoku bijon). Ministry of Health, Labor, and Welfare (MHLW). www.mhlw.go.jp/file/06-Seisakujouhou-11120000Iyakushokuhinkyoku/honbun_3.pdf. (in Japanese). Accessed June 20, 2017.

8. Annual report of JPA: 2014-2015. Japan Pharmaceutical Association. www.nichiyaku.or.jp. Accessed July 25, 2017.

9. Hagemeier NC, Hess, R Jr., Hagen KS, Sorah EL. Impact of an interprofessional communication course on nursing, medical and pharmacy students' communication skill self-efficacy beliefs. Am J Pharm Educ. 2014;78(10):Article 186.

10. Lane C, Rollnick S. The use of simulated patients and role-play in communication skills training: a review of the literature to August 2005. Patient Educ Couns. 2007 Jul;67(1-2):13-20.

11. The Model Core Curriculum for Pharmacy Education, 2013 ed. [translated from Yakugaku Kyouiku Moderu Koa Karikyuramu. Heisei 25nen 12gatsu 25nichi]. 2013:20-21,84-85,92. Ministry of Education, Culture, Science, and Technology (MEXT). Dec 2013. www.mext.go.jp/component/a_menu/education/detail/_icsFiles/ afieldfile/2015/02/12/1355030_01.pdf. Accessed July 25, 2017 12. Clinical pharmacy guidelines 2015. (translated from Yakugaku Jitsumu Jisshu ni Kansuru Gaidorain). Ministry of Education, Science, and Technology in Japan (MEXT). www.mext.go.jp/ b_menu/shingi/chousa/koutou/058/gaiyou/1355408.htm. (in Japanese). Accessed June 20, 2017.

13. Okada H. Aiming for 3-star pharmacists. (Translated from: Three-star pharmacists wo mesase!) Tokyo: Jiho Publishing; 2013:68;45-46;55-56.

14. Puspitasari HP, Aslani P, Krass I. A review of counseling practices on prescription medicines in community pharmacies. Res Social Adm Pharm. 2009;5:197-210.
15. Albrecht $\mathrm{S}$. The pharmacist's role in medication adherence. US Pharm. 2011;36(5):43-48. www.uspharmacist.com/content/d/ feature/i/1500/c/28121. Accessed July 4, 2017.

16. Kimberlin CL. Communicating with patients: skills assessment in US colleges of pharmacy. Am J Pharm Educ. 2006;70(3):Article 67. www.ajpe.org/doi/pdf/10.5688/aj700367. Accessed July 4, 2017. 17. Wallman A, Vaudan C, Sporrong SK. Communications training in pharmacy education, 1995-2010. Am J Pharm Educ.

2013;77(2):Article 36.

18. Kurtz SM, Silverman JD. Calgary-Cambridge guide to the medical interview - Communication Process. 1998.

19. gp-training.net/training/communication_skills/calgary/ calgary.pdf. Accessed June 22, 2017.

20. Makoul G. The SEGUE Framework for teaching and assessing communication skills. Patient Educ Couns. 2001;45(1):23-34.

21. Teramachi H, Komada N, Tanizawa K, Kuzuya Y, Tsuchiya T. Development of skill scale for communication skill measurement of pharmacist. Yakugaku Zasshi. 2011;131(4):587-595. https://

www.ncbi.nlm.nih.gov/pubmed/?term=kiss-18. Accessed July 4, 2017. 22. Tavakol M, Dennick R. Making sense of Cronbach's alpha. Int $J$ Med Educ. 2011;2:53-55. www.ijme.net/archive/2/cronbachsalpha.pdf. Accessed March 20, 2017.

23. SAS Institute Inc. JMP 12 basic analysis. Cary (NC): SAS Institute Inc.; 2015.

24. Laerd Statistics: Wilcoxon signed-rank test using SPSS statistics. Lund Research Ltd. 2013. https://statistics.laerd.com/spss-tutorials/ wilcoxon-signed-rank-test-using-spss-statistics.php. Accessed December 20, 2017.

25. Wuench KL. An introduction to path analysis [tutorial]. 2016. http://core.ecu.edu/psyc/wuenschk/MV/SEM/Path.pdf. Accessed July 13, 2017.

26. Schreiber JB, Nora A, Stage FK, Barlow EA, King J. Reporting structural equation modeling and confirmatory factor analysis results: a review. J Educ Res. 2006;99(6):323-338. http://

www.tandfonline.com/doi/abs/10.3200/JOER.99.6.323-338.

Accessed July 13, 2017.

27. Arbuckle JL. IBM SPSS Amos 24 user's guide. Chicago (IL): IBM Software Group; 2016.

28. Cohen J. Statistical Power Analysis for the Behavioral Sciences. New York: Routledge; 1988.

29. McNemar Q. Note on the sampling error of the difference between correlated proportions or percentages. Psychometrika. 1947 Jun;12(2):153-157.

30. Ofstad W, Brunner LJ. Team-based learning in pharmacy education. Am J Pharm Educ. 2013;77(4):Article 70.

31. Lindenmeyer A, Hearnshaw H, Vermeire E, Van Royen P, Wens $\mathrm{J}$, Biot Y. Interventions to improve adherence to medication in people with type 2 diabetes mellitus: a review of the literature on the role of pharmacists. J Clin Pharm Ther. 2006;31(5):409-419. 


\section{American Journal of Pharmaceutical Education 2019; 83 (5) Article 6745.}

Appendix 1. Communication Questionnaire for Fourth-Year Pre-clerkship Students

Pre-clerkship Communication Questionnaire, Parts 1, 2, and 4 Questions

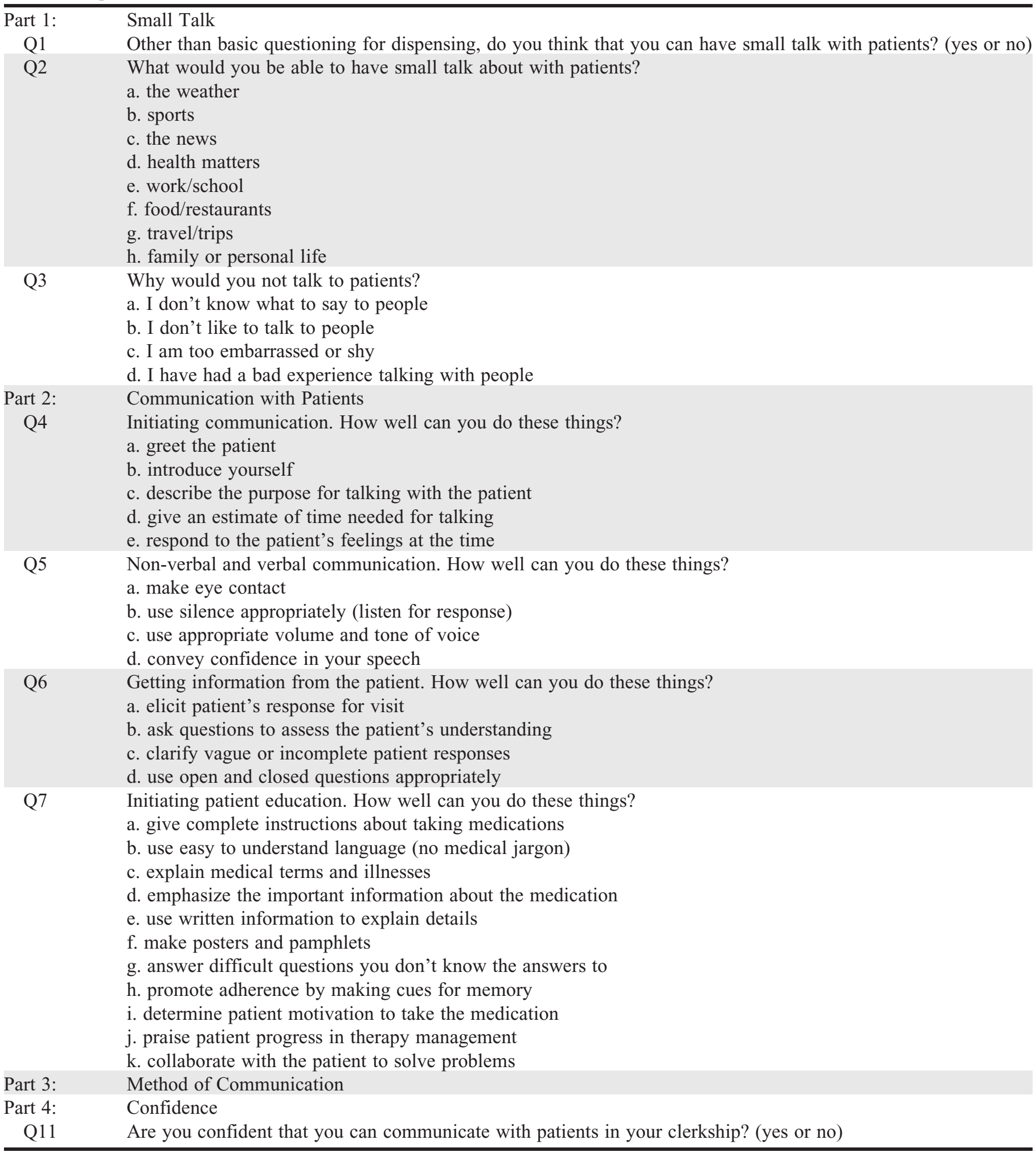

Q8, Q9, and Q10 were omitted as they do not relate to the study 